\title{
Empty Sella Syndrome in a Postmenopausal Woman
}

\author{
SHEFIN SM ${ }^{\mathrm{a}}$, QURESHI NK ${ }^{\mathrm{b}}$
}

\begin{abstract}
Summary:
A 50-year-old, prematurely postmenopausal diabetic woman was admitted in the Endocrinology department of BIRDEM with the complaints of vomiting, loose motion, lethargy, profound weakness. Previously she suffered from several episodes of electrolyte imbalance and after investigations adrenal insufficiency was diagnosed on 2010. No evaluation was done for her premature menopause. During this episode of illness, she was found with postural hypotension,
\end{abstract}

\section{Introduction:}

Empty sella syndrome (ESS) is a condition in which the pituitary gland shrinks or becomes flattened. It is a radiological finding where spinal fluid is found within the space created for the pituitary that is sella turcica which in Latin means "Turkish saddle.", a bony structure at the base of the brain that surrounds and protects the pituitary gland (figure 1). This condition that is often discovered during tests for pituitary disorders, when radiological imaging of the pituitary gland reveals a sella turcica that appears to be empty. Empty Sella Syndrome is a rare disorder that rarely affects males. It usually affects overweight middle-aged women, but in very rare cases it may be found in children ${ }^{1}$.

This condition is classified into two verities, primary and secondary empty sella syndrome. Primary ESS, a rare inherited disorder of the brain that is transmitted as an autosomal dominant trait, can develop as a consequence of a primary congenital weakness of the diaphragm in a patient with no evident secondary cause.

a. Dr. Sultana Marufa Shefin MD(EM), Registrar, Department of Endocrinology, Ibrahim Medical College \& BIRDEM hospital, Dhaka, Bangladesh.

b. Dr. Nazmul Kabir Qureshi MD (EM), BIRDEM Academy, Dhaka, Bangladesh.

Address of Correspondence: Dr. Sultana Marufa Shefin, MD (EM), Registrar, Department of Endocrinology, Ibrahim Medical College \& BIRDEM hospital, Room No: 1535, BIRDEM, Shahbag, Dhaka, Bangladesh. Email: shefin_neon@yahoo.com

Received: May 05, 2011

Accepted: July 30, 2011 hyponatremia, dyslipidemia and panhypopituitarism. MRI of sella and parasellar region was done which revealed features suggestive of empty sella. This case gives insight that early menopause warrants proper evaluation and during evaluation, along with other factors hypopituitarism should be considered as an etiology for this condition.

Key words: Empty sella syndrome, postmenopausal woman.

(Birdem Med J 2012; 2(1): 52-55)

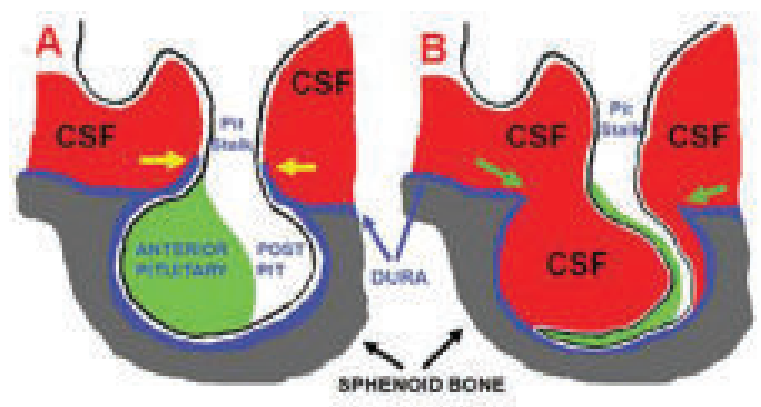

Fig.-1: Formation of empty sella.

Here a small anatomical defect above the pituitary gland increases pressure in the sella turcica and causes the gland to flatten out along the interior walls of the sella turcica cavity. Symptoms and findings may include unusual facial features, a highly-arched palate, moderate short stature, increased bone density (osteosclerosis), and normal pituitary function. Primary ESS is associated with obesity and high blood pressure in women. Up to $50 \%$ of patients with primary empty sella syndrome have associated benign intracranial hypertension ${ }^{2}$.

Individuals with secondary ESS due to destruction of the pituitary gland may have symptoms that reflect the loss of pituitary functions, such as the ceasing of menstrual periods, infertility, fatigue, and intolerance to stress and infection ${ }^{3}$. In children, ESS may be associated with early onset of puberty, growth hormone deficiency, pituitary tumors, or pituitary gland dysfunction. Some cases are of idiopathic variety. In 
the idiopathic form of the disease, the exact cause in not known. This form of the disorder affects mostly obese, middle-aged women.

Generally, in this syndrome, pituitary function is normal, but a number of patients may have headaches, visual disturbance, allergic rhinitis, low sex drive, obesity, hair loss, mild hyperprolactinemia, galactorrhea, erectile dysfunction and irregular menses. In most cases, the pituitary functions normally as evidenced by normal thyroid functions, normal tests of adrenal function, normal somatomedin-C levels, and regular menses. However, if greater than $90 \%$ of pituitary tissue is compressed or atrophied, pituitary failure occurs ${ }^{3}$. Hypopituitarsim is manifested by diminished or absent secretion of one or more pituitary hormones. The development of signs and symptoms is often slow and insidious, depending on the rate of onset and magnitutte of hypothalamic-pituitary damage ${ }^{4}$. ACTH deficiency causes adrenocrtical deficiency and its clinical features resemble those of primary adrenal failure. Because of its gradual onset, symptoms of secondary adrenal insufficiency may go undetected for prolonged period, becoming manifested only during periods of stress ${ }^{5}$. Hypogonadism is manifested by amenorrhoea in women with hypopituitarism ${ }^{6}$.

\section{Case report:}

Mrs. X, 50-year-old diabetic woman, hailing from Chittagong, got admitted in BIRDEM on 02/01/11 with the complaints of recurrent vomiting occurring 3-4 times in a day, anorexia, loose motion for several times, lethargy and profound generalized weakness for last 10 days. On query, she gave no history of unconsciousness or syncope. In 2010, she suffered from of repeated electrolyte imbalance and after investigations she was diagnosed as a case of adrenal insufficiency. Thereafter, she was put on steroid which she took irregularly and totally discontinued for last 3 months before this episode of illness.

She had her menarche at 12 years of age. She had two children. Her obstetrics and lactation history was uneventful. She had her menopause at 39 year of age and then no investigation was carried out for her premature menopause. There was no family history of diabetes mellitus, hypertension, adrenal or other autoimmune diseases.
On examination, her BMI was $21 \mathrm{~kg} / \mathrm{m} 2$. Thyroid Gland was not enlarged. Her pulse was $92 / \mathrm{min}$. Recorded blood pressure was $110 / 70 \mathrm{~mm}$ of $\mathrm{Hg}$ with postural hypotension during examination. Other general \& systemic examination reveals normal findings. On this clinical scenario our provisional diagnosis for this premature menopaused woman was adrenal insufficiency with diabetes mellitus.

Important investigations were done that day and reports are as follows: $\mathrm{Hb} \%-10.4 \mathrm{gm} / \mathrm{dl}$, ESR-15mm in $1 \mathrm{st}$ Hour. SGPT-39U/L,SGOT-16U/L,S.Bili-0.5mg/d, HbA1C\%$10.6 \%$, S. creatinine- $0.6 \mathrm{mg} / \mathrm{dl}$, S.Chol-220, TG-122, HDL-36, LDL-160. Serum Na, K, Cl and TCO2 in $\mathrm{mmol} / \mathrm{L}$ were 109, 3.7, 76 and 26 respectively. On 11/ $01 / 11$ after steroid replacement values of those were 137, 4.6, 91 and 36 respectively. Hormone study reports were as follows: Basal cortisol - $105 \mathrm{nmol} / \mathrm{L}$ [1161065], S.ACTH -14.80 pg/ml[8.3-57.8], FSH -5.61 $\mathrm{mIU} / \mathrm{ml}[3.2-10.0], \mathrm{LH}-1.29 \mathrm{mIU} / \mathrm{ml}$, S.Prolactin $352.83 \mathrm{mIU} / \mathrm{ml}[66-1065]$, TSH $-0.37 \mathrm{microIU} / \mathrm{ml}$ [0.475.01], FT4 -8.58 pmol/L[ 9.14-23.18], which indicated panhypopituitarism. Considering the above reports, MRI of sella and parasellar region was done that showed features suggestive of empty sella (figure 2).

After considering all the clinical parameters and investigation reports we concluded that this prematurely

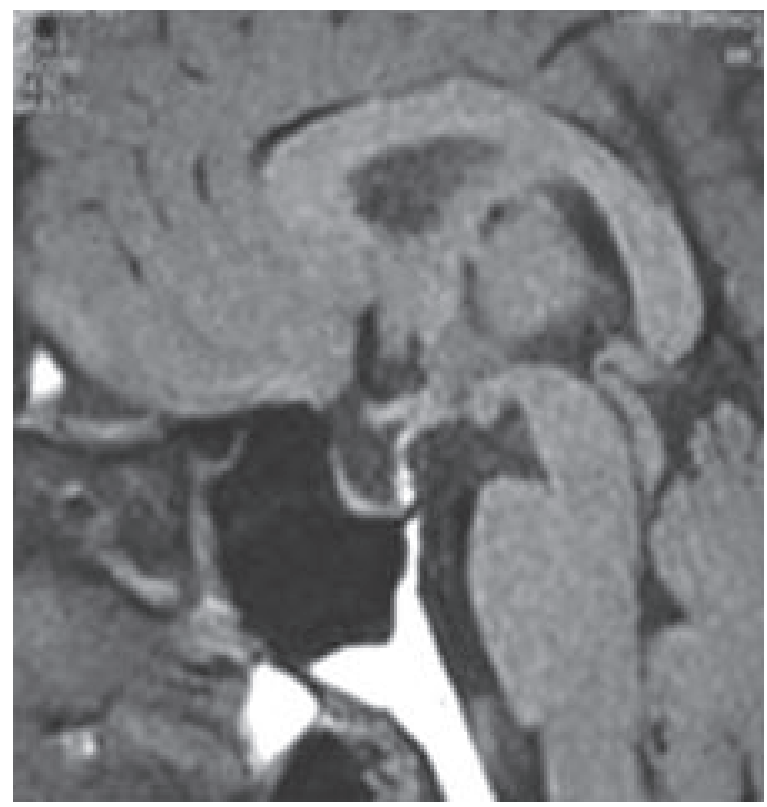

Fig.-2: MRI of sella and parasellar region showing empty sella. 
postmenopausal woman had been suffering from panhypopituitarism due to Empty sella Syndrome with diabetes mellitus and dyslipidemia. A thorough counseling was done with the patient about her diagnosis, treatment option, follow up plans and sick days instructions and management. Feedback of the education was taken from her. Gradually oral steriod, then thyroxin were started. The patient was discharged successfully with a follow up plan after one month with the reports of serum electrolytes and $\mathrm{FT}_{4}$.

\section{Discussion:}

For reasons unclear, empty sella occur predominantly in obese adult women, many of whom have hypertension and diabetes. Conditions that may suggest empty sella syndrome are hypertension, hypogonadism, hyperprolactinemia, adrenal insufficiency, low DHEA level, hypothyroidism, low estrogen level, hypertriglyceridemia ${ }^{3}$. Differential diagnoses of Empty Sella Syndrome are Achard-Thiers Syndrome, Craniopharingiomas, Meningiomas, Optic Glioma, etc. Achard-Thiers Syndrome is characterized by diabetes, virilization in post-menopausal women ${ }^{7}$. Ruptured intrasellar epithelial cyst may also lead to development of empty sellar syndrome ${ }^{8}$. MRI scans are useful in evaluating ESS and differentiating it from other disorders that produce an enlarged sella ${ }^{9}$. With sensitive MRI techniques for pituitary visualization, several anatomic features characteristics of hypopituitarism become apparent. Evidence for acquired pituitary gland damage or destruction is clearly visible on MRI and patients presenting with hypopituitarism of undetermined etiology can exhibit decreased gland volume, partial or complete empty sella ${ }^{10}$. Unless the syndrome results in other medical problems, treatment for endocrine dysfunction associated with pituitary malfunction is symptomatic and supportive. There is no specific treatment for primary empty sella syndrome if pituitary function is normal. Individual hormone replacement may be required when the pituitary gland is failing to control the output of other endocrine glands. These hormones include thyroid hormones, cortisol, DHEA and human growth hormone. Bromocriptine may be prescribed if the prolactin levels are high and interfering with function of the ovaries or testes. Treatment for secondary empty sella syndrome involves replacing the hormones that are lacking. In some cases, surgery may be need. Complications of primary empty sella syndrome include mild hyperprolactinemia. Complications of secondary empty sella syndrome are related to the cause or to the effects of too little pituitary hormone

Evaluation of female reproductive function depends upon a detailed history of menses. Approximately $90 \%$ of women experience menopause at a mean age of 51.2 years of age. The remainder experience menopause prior to age of 46 years which is often termed as early menopause. With $1 \%$ women experience menopause before 40 year age which is termed as premature menopause ${ }^{11}$. Cessation of menstrual periods in women is one of the presentations of panhypopituitarism ${ }^{12}$. Dysfunction due to gonadotropins deficiency due to hypopituitarism is established by the constellation of abnormal mens or amenorrhoea with no elevated LH and FSH in women ${ }^{13}$.

In our case, this middle age women with normal BMI, was suffering from panhypopituitarism due to empty sella syndrome, diabetes mellitus, dyslipidemia. Her prolactin level was normal. No causes of secondary ESS could be identified for this patient from clinical history, investigation reports or medical records review. She had premature menopause at the age of 39 years but no evaluation was done to find out reason behind it until this admission and the case ended up with the diagnosis of panhypopituitarism. This case gives insight that early menopause warrants proper evaluation and during evaluation, along with other factors, panhypopituitarism should be considered as an etiology for such condition.

\section{References:}

1. Costigan DC. The "empty sella" in childhood. Clin Pediatr 1984; 23(8): 437-40.

2. De Marinis L, Bonadonna S, Bianchi A, et al. Primary empty sella. J Clin Endocrinol Metab 2005; 90:5471-77.

3. Melmed S, Kleinberg D. Anterior pituitary. In: Kronenberg HM, Melmed S, Polonsky KS, Larsen PR, eds. Williams Textbook of Endocrinology. Philadelphia, PA: Saunders Elsevier; 2008. 239-40.

4. Aron DC. Hypothalamus and Pituitary Gland. In: Gardner DG, Shoback D. Greenspan's Basic and Clinical Endocrinology $8^{\text {th }}$ ed. McGraw Hill Medical; New York, USA. 2007.P.134.

5. Aron DC. Hypothalamus and Pituitary Gland. In: Gardner DG, Shoback D. Greenspan's Basic and Clinical Endocrinology $8^{\text {th }}$ ed. McGraw Hill Medical; New York, USA. 2007.P.137. 
6. Aron DC. Hypothalamus and Pituitary Gland. In: Gardner DG, Shoback D. Greenspan's Basic and Clinical Endocrinology $8^{\text {th }}$ ed. McGraw Hill Medical; New York, USA. 2007. P136.

7. http.//arachnoidcyst.org/empty.html.

8. Raiti S, Albrink, MJ. Empty Sella Syndrome Secondary to Intrasellar Cyst in Adolescence. Am J Dis Child 1976; 130(9):1009-12.

9. Naheedy MH. MRI and CT of sellar and parasellar disorders. Radiol Clin North Am 1987; 25(4): 819-47.

10. Melmed S, Kleinberg D. Anterior pituitary. In: Kronenberg HM, Melmed S, Polonsky KS, Larsen PR, eds. Williams
Textbook of Endocrinology. Philadelphia, PA: Saunders Elsevier; 2008. 235.

11. Rosen MP, Cedars MI. Female Reproductive Endocrinology and Infertility. In: Gardner DG, Shoback D. es. Greenspan's Basic and Clinical Endocrinology $8^{\text {th }}$ ed. New York, USA. McGraw Hill Medical; 2007. 537.

12. http://www.nlm.nih.gov/medicineplus/ency/article/ 000343.htm.

13. Melmed S, Kleinberg D. Anterior pituitary. In: Kronenberg HM, Melmed S, Polonsky KS, Larsen PR, eds. Williams Textbook of Endocrinology. Philadelphia, PA: Saunders Elsevier; 2008. 241. 